\title{
Crystal structure of dichlorido-octamethyl-bis $\left(\mu_{3^{-}}\right.$ oxido)-bis $\left(\mu_{2}-2\right.$-(phenylamino)ethanolato- $\left.{ }^{2} 0: 0\right)$ tetratin(IV), $\mathrm{C}_{24} \mathrm{H}_{44} \mathrm{Cl}_{2} \mathrm{~N}_{2} \mathrm{O}_{4} \mathrm{Sn}_{4}$
}

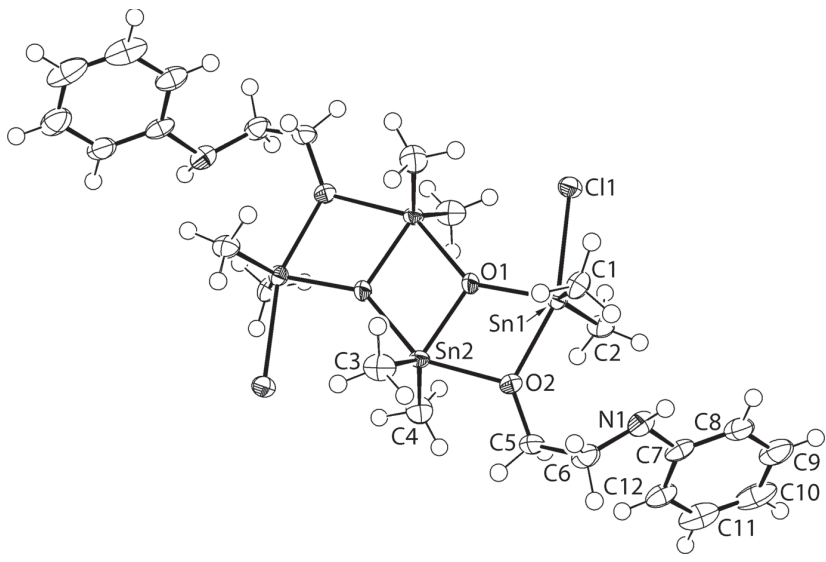

https://doi.org/10.1515/ncrs-2019-0567

Received August 5, 2019; accepted September 22, 2019; available online October 9, 2019

\begin{abstract}
$\mathrm{C}_{24} \mathrm{H}_{44} \mathrm{Cl}_{2} \mathrm{~N}_{2} \mathrm{O}_{4} \mathrm{Sn}_{4}$, orthorhombic, Pbca (no. 61), $a=13.9593(2) \AA, \quad b=11.1227(2) \AA, \quad c=21.6656(3) \AA$, $V=3363.91(9) \AA^{3}, Z=4, R_{\mathrm{gt}}(F)=0.0252, w R_{\text {ref }}\left(F^{2}\right)=0.0642$, $T=100(2) \mathrm{K}$.
\end{abstract}

CCDC no.: 1955109

The molecular structure is shown in the figure. Table 1 contains crystallographic data and Table 2 contains the list of the atoms including atomic coordinates and displacement parameters.

\section{Source of material}

All chemicals and solvents were used as purchased without purification. The melting point of the compound was measured on a Mel-Temp II digital melting point apparatus and

\footnotetext{
*Corresponding author: Edward R.T. Tiekink, Research Centre for Crystalline Materials, School of Science and Technology, Sunway University, 47500 Bandar Sunway, Selangor Darul Ehsan, Malaysia, e-mail: edwardt@sunway.edu.my. https://orcid.org/0000-00031401-1520

Kong Mun Lo and See Mun Lee: Research Centre for Crystalline Materials, School of Science and Technology, Sunway University, 47500 Bandar Sunway, Selangor Darul Ehsan, Malaysia
}

Table 1: Data collection and handling.

\begin{tabular}{|c|c|}
\hline Crystal: & Colourless prism \\
\hline Size: & $0.16 \times 0.12 \times 0.06 \mathrm{~mm}$ \\
\hline Wavelength: & Cu $K \alpha$ radiation (1.54178 $\mathrm{A})$ \\
\hline$\mu:$ & $25.0 \mathrm{~mm}^{-1}$ \\
\hline Diffractometer, scan mode: & XtaLAB Synergy, $\omega$ \\
\hline$\theta_{\max }$, completeness: & $67.1^{\circ},>99 \%$ \\
\hline$N(h k l)_{\text {measured }}, N(h k l)_{\text {unique }}, R_{\text {int }}:$ & $21693,3006,0.042$ \\
\hline Criterion for $I_{\mathrm{obs}}, N\left(h k l_{\mathrm{gt}}\right.$ : & $I_{\mathrm{obs}}>2 \sigma\left(I_{\mathrm{obs}}\right), 2840$ \\
\hline$N(\text { param })_{\text {refined }}:$ & 170 \\
\hline Programs: & $\begin{array}{l}\text { CrysAlis }{ }^{\text {PRO }}[1] \text {, SHELX }[2,3] \text {, } \\
\text { WinGX/ORTEP [4] }\end{array}$ \\
\hline
\end{tabular}

was uncorrected. The IR spectrum was recorded on a PerkinElmer RX1 spectrophotometer in the range 4000 to $400 \mathrm{~cm}^{-1}$.

The dithiocarbamate salt, $\mathrm{K}\left[\mathrm{S}_{2} \mathrm{CN}(\mathrm{Ph}) \mathrm{CH}_{2} \mathrm{CH}_{2} \mathrm{OH}\right]$, was prepared in situ (methanol) from the reaction of $\mathrm{CS}_{2}$ (Merck, $0.25 \mathrm{mmol}$ ) with 2-anilinoethanol (Merck, $0.25 \mathrm{mmol}$ ) and $\mathrm{KOH}(0.03 \mathrm{~mL} ; 50 \% \mathrm{w} / \mathrm{v})$; $\mathrm{CS}_{2}$ was added dropwise into the methanolic solution $(10 \mathrm{~mL})$. The resulting mixture solution was kept at $273 \mathrm{~K}$ for $0.5 \mathrm{~h}$. Dimethyltin dichloride $(0.25 \mathrm{mmol}, 0.05 \mathrm{~g})$ in methanol $(10 \mathrm{~mL})$ was added to the prepared salt. The resulting mixture was stirred and refluxed for $2 \mathrm{~h}$. The filtrate was evaporated slowly until a white precipitate was formed. The precipitate was recrystallised from methanol and dimethylformamide. The title molecule was isolated as a side-product obtained from the slow evaporation of the solvent. Yield: $0.02 \mathrm{~g}(16 \%)$. M.pt: $>573 \mathrm{~K}$. IR $\left(\mathrm{cm}^{-1}\right)$ $467(\mathrm{w}) v(\mathrm{Sn}-\mathrm{O}), 1487(\mathrm{~m}) \mathrm{v}(\mathrm{C}-\mathrm{N}), 1018(\mathrm{~s}) \mathrm{v}(\mathrm{C}-\mathrm{O})$.

\section{Experimental details}

The $\mathrm{C}$-bound $\mathrm{H}$ atoms were geometrically placed $(\mathrm{C}-$ $\mathrm{H}=0.95-0.99 \AA$ ) and refined as riding with $U_{\text {iso }}(\mathrm{H})=1.2-$ $1.5 U_{\text {eq }}(\mathrm{C})$. The $\mathrm{N}$-bound $\mathrm{H}$-atom was located in a difference Fourier map but was refined with a distance restraint of $\mathrm{N}-\mathrm{H}=0.88 \pm 0.01 \AA$, and with $U_{\text {iso }}(\mathrm{H})$ set to $1.2 U_{\text {eq }}(\mathrm{N})$.

\section{Comment}

Diorganotin dichloride molecules are well-known to be subject to hydrolysis $[5,6]$ and it was in this context the crystals of the title tetra-tin oxido-cluster $\left\{\left[\left(\mathrm{Me}_{2} \mathrm{SnCl}\right)\left(\mathrm{Me}_{2} \mathrm{Sn}\right)\left(\mathrm{OCH}_{2} \mathrm{CH}_{2} \mathrm{~N}(\mathrm{H}) \mathrm{Ph}\right)\right] \mathrm{O}\right\}_{2}$, (I), was isolated. 
Table 2: Fractional atomic coordinates and isotropic or equivalent isotropic displacement parameters $\left(\AA^{2}\right)$.

\begin{tabular}{|c|c|c|c|c|}
\hline Atom & $x$ & $y$ & $z$ & $U_{\text {iso }} * / U_{\text {eq }}$ \\
\hline Sn1 & $0.53720(2)$ & $0.28294(2)$ & $0.47533(2)$ & $0.01347(9)$ \\
\hline $\mathrm{Sn} 2$ & $0.46391(2)$ & $0.01011(2)$ & $0.42686(2)$ & $0.01254(9)$ \\
\hline $\mathrm{Cl} 1$ & $0.59652(6)$ & $0.30565(8)$ & $0.58783(4)$ & $0.01838(18)$ \\
\hline 01 & $0.51453(17)$ & $0.1109(2)$ & $0.49898(11)$ & $0.0165(5)$ \\
\hline 02 & $0.47623(17)$ & $0.1953(2)$ & $0.39460(12)$ & $0.0180(5)$ \\
\hline N1 & $0.5083(2)$ & $0.4455(3)$ & $0.34412(15)$ & $0.0203(7)$ \\
\hline $\mathrm{H} 1 \mathrm{~N}$ & $0.480(3)$ & $0.510(2)$ & $0.360(2)$ & $0.024^{\star}$ \\
\hline C1 & $0.4119(2)$ & $0.3840(3)$ & $0.49237(18)$ & $0.0188(7)$ \\
\hline $\mathrm{H} 1 \mathrm{~A}$ & 0.3558 & 0.3315 & 0.4893 & $0.028^{*}$ \\
\hline $\mathrm{H} 1 \mathrm{~B}$ & 0.4068 & 0.4487 & 0.4618 & $0.028^{\star}$ \\
\hline $\mathrm{H} 1 \mathrm{C}$ & 0.4151 & 0.4188 & 0.5339 & $0.028^{\star}$ \\
\hline $\mathrm{C} 2$ & $0.6758(2)$ & $0.3090(4)$ & $0.43797(17)$ & $0.0200(8)$ \\
\hline $\mathrm{H} 2 \mathrm{~A}$ & 0.6890 & 0.2463 & 0.4074 & $0.030^{*}$ \\
\hline $\mathrm{H} 2 \mathrm{~B}$ & 0.7234 & 0.3047 & 0.4711 & $0.030^{*}$ \\
\hline $\mathrm{H} 2 \mathrm{C}$ & 0.6791 & 0.3881 & 0.4181 & $0.030^{*}$ \\
\hline $\mathrm{C} 3$ & $0.3131(3)$ & $0.0038(4)$ & $0.42892(19)$ & $0.0243(9)$ \\
\hline $\mathrm{H} 3 \mathrm{~A}$ & 0.2906 & 0.0202 & 0.4709 & $0.036^{*}$ \\
\hline $\mathrm{H} 3 \mathrm{~B}$ & 0.2914 & -0.0762 & 0.4161 & $0.036^{*}$ \\
\hline $\mathrm{H} 3 \mathrm{C}$ & 0.2871 & 0.0645 & 0.4007 & $0.036^{*}$ \\
\hline $\mathrm{C} 4$ & $0.5720(3)$ & $-0.0579(4)$ & $0.36759(19)$ & $0.0238(8)$ \\
\hline $\mathrm{H} 4 \mathrm{~A}$ & 0.6352 & -0.0416 & 0.3855 & $0.036^{\star}$ \\
\hline $\mathrm{H} 4 \mathrm{~B}$ & 0.5673 & -0.0187 & 0.3272 & $0.036^{*}$ \\
\hline $\mathrm{H} 4 \mathrm{C}$ & 0.5637 & -0.1449 & 0.3626 & $0.036^{\star}$ \\
\hline C5 & $0.4829(3)$ & $0.2247(3)$ & $0.33104(18)$ & $0.0216(8)$ \\
\hline $\mathrm{H} 5 \mathrm{~A}$ & 0.4448 & 0.1666 & 0.3067 & $0.026^{*}$ \\
\hline $\mathrm{H} 5 \mathrm{~B}$ & 0.5505 & 0.2183 & 0.3176 & $0.026^{*}$ \\
\hline $\mathrm{C} 6$ & $0.4466(3)$ & $0.3514(4)$ & $0.31875(18)$ & $0.0232(8)$ \\
\hline $\mathrm{H} 6 \mathrm{~A}$ & 0.4410 & 0.3632 & 0.2736 & $0.028^{*}$ \\
\hline $\mathrm{H} 6 \mathrm{~B}$ & 0.3818 & 0.3598 & 0.3368 & $0.028^{*}$ \\
\hline $\mathrm{C} 7$ & $0.5856(3)$ & $0.4890(3)$ & $0.30925(18)$ & $0.0200(8)$ \\
\hline $\mathrm{C} 8$ & $0.6262(3)$ & $0.6010(4)$ & $0.32490(18)$ & $0.0255(8)$ \\
\hline $\mathrm{H} 8$ & 0.5995 & 0.6463 & 0.3579 & $0.031^{*}$ \\
\hline C9 & $0.7039(3)$ & $0.6458(4)$ & $0.2931(2)$ & $0.0334(10)$ \\
\hline H9 & 0.7300 & 0.7218 & 0.3040 & $0.040^{*}$ \\
\hline C10 & $0.7444(3)$ & $0.5798(5)$ & $0.2449(2)$ & $0.0373(11)$ \\
\hline $\mathrm{H} 10$ & 0.7984 & 0.6098 & 0.2231 & $0.045^{\star}$ \\
\hline C11 & $0.7046(3)$ & $0.4702(5)$ & $0.2294(2)$ & $0.0342(11)$ \\
\hline $\mathrm{H} 11$ & 0.7320 & 0.4246 & 0.1968 & $0.041^{*}$ \\
\hline C12 & $0.6259(3)$ & $0.4255(4)$ & $0.26014(18)$ & $0.0248(8)$ \\
\hline $\mathrm{H} 12$ & 0.5988 & 0.3509 & 0.2478 & $0.030^{*}$ \\
\hline
\end{tabular}

The difficulties associated with hydrolysis notwithstanding, recent work has highlighted the potential anti-tumour activity of related tetra-tin oxido clusters [7, 8], a well-documented attribute of organotin compounds [9]. Herein, the crystal and molecular structures of (I) are described.

The molecular structure of (I) is shown in the figure (70\% displacement ellipsoids; unlabelled atoms are related by the symmetry operation (i) $1-x,-y, 1-z$ ); the entire molecule is generated by the application of a crystallographic centre of inversion. The molecule is constructed about a central $\mathrm{Sn}_{2} \mathrm{O}_{2}$ core, containing endocyclic $\mathrm{Sn} 2$ atoms. The $\mu_{3^{-}}$ 01 oxido atom of the core also binds to an exocyclic Sn1 atom. Further links between the Sn1 and Sn2 atoms are provided by a $\mu_{2}-\mathrm{O} 2$ alkoxide atom. The coordination geometry for the $\mathrm{Sn} 1$ atom is completed by two methyl groups and a chloride atom $[\mathrm{Sn} 1-\mathrm{Cl} 1=2.5866(9) \AA]$, while that of the Sn2 atom is completed by two methyl substituents. Within the core, the Sn2-01, $01^{\mathrm{i}}$ bond lengths of 2.049(2) and 2.118(2) $\AA$, respectively, and the $01-\mathrm{Sn} 2-01^{\mathrm{i}}=73.76(10)^{\circ}$ and Sn2-O1$\mathrm{Sn} 2^{\mathrm{i}}=106.24(10)^{\circ}$ bond angles indicate the core has the shape of a distorted rhombus. The Sn1-02 [2.176(3) Å] and Sn2-02 [2.181(3) $\AA$ ] bond lengths indicate the $\mu_{2}-\mathrm{O}$ (alkoxide) bridge is symmetric. Each of the penta-coordinate geometries is highly distorted. For the $\mathrm{Sn} 1$ atom, the donor set is defined by $\mathrm{C}_{2} \mathrm{ClO}_{2}$ atoms with the widest angle defined by the $\mathrm{Cl} 1$ and $\mathrm{O} 2$ atoms $\left[\mathrm{Cl1}-\mathrm{Sn} 1-\mathrm{O} 2=157.89(7)^{\circ}\right]$ whereas for the $\mathrm{Sn} 2$ atom, the widest angle in the $\mathrm{C}_{2} \mathrm{O}_{3}$ geometry is defined by the $\mathrm{O} 2$ and $01^{\mathrm{i}}$ atoms $\left[02-\mathrm{Sn} 2-01^{\mathrm{i}}=146.31(9)^{\circ}\right]$. The next widest angles are subtended by the tin-bound methyl substituents $\left[\mathrm{C} 1-\mathrm{Sn} 1-\mathrm{C} 2=138.66(15)^{\circ}\right.$ and $\mathrm{C} 3-\mathrm{Sn} 2-$ $\left.\mathrm{C} 4=135.40(16)^{\circ}\right]$. The value of $\tau$ is a parameter that quantifies five-coordinate geometries, equalling 0.0 for an ideal square-pyramidal coordination geometry and 1.0 for an ideal trigonal-bipyramid [10]. In (I), $\tau=0.32$ for the Sn1 atom and $\tau=0.18$ for the Sn2 atom, each indicative of tendancies towards a square-pyramidal coordination geometry. The sequence of three edge-shared $\mathrm{Sn}_{2} \mathrm{O}_{2}$ rhombi have the shape of a kinked ladder.

The most prominent feature of the molecular packing is the formation of amine- $\mathrm{N}-\mathrm{H} \cdots \mathrm{Cl}$ hydrogen bonds [N1$\mathrm{H} 1 \mathrm{n} \cdots \mathrm{Cl}^{\mathrm{ii}}: \mathrm{H} 1 \mathrm{n} \cdots \mathrm{Cl}{ }^{\mathrm{ii}}=2.57(3) \AA \mathrm{N}, \mathrm{N} 1 \cdots \mathrm{Cl} 1^{\mathrm{ii}}=3.461(3) \AA$ with angle at $\mathrm{H} 1 \mathrm{n}=177(2)^{\circ}$ for (ii) $1-x, 1-y, 1-z$ ]. These give rise to a linear supramolecular chain along the $b$-axis direction. The chains are linked into a supramolecular layer in the $b c$-plane by weak methylene- $\mathrm{C}-\mathrm{H} \cdots \pi$ (phenyl) interactions $\left[\mathrm{C} 5-\mathrm{H} 5 \cdots \mathrm{Cg}(\mathrm{C} 7-\mathrm{C} 12)^{\mathrm{iii}}: \mathrm{H} 5 \cdots \mathrm{Cg}(\mathrm{C} 7-\mathrm{C} 12)^{\mathrm{iii}}=2.79 \AA\right.$, $\mathrm{C} 5 \cdots \mathrm{Cg}(\mathrm{C} 7-\mathrm{C} 12)^{\mathrm{iii}}=3.766(4) \AA$ with angle at $\mathrm{H} 5=170^{\circ}$ for (iii) $1-x,-1 / 2+y, 1 / 2-z$ ]. Layers stack along the $a$-axis without significant directional interactions between them.

Finally, the Hirshfeld surfaces and two-dimensional fingerprint (full and decomposed) plots were calculated on the entire tetra-tin oxido-cluster using Crystal Explorer 17 [11] and standard procedures [12]. This analysis points to the significance of $\mathrm{H} \cdots \mathrm{H}$ contacts which contribute $76.0 \%$ of all contacts to the Hirshfeld surface. The only other two contacts registered are $\mathrm{C} \cdots \mathrm{H} / \mathrm{H} \cdots \mathrm{C}[12.7 \%]$ and $\mathrm{Cl} \cdots \mathrm{H} / \mathrm{H} \cdots \mathrm{Cl}$ $[10.9 \%]$.

Acknowledgements: Sunway University Sdn Bhd is thanked for financial support of this work through Grant no. STRRCTR-RCCM-001-2019. 


\section{References}

1. Agilent Technologies: CrysAlis ${ }^{\mathrm{PRO}}$. Agilent Technologies, Santa Clara, CA, USA (2010).

2. Sheldrick, G. M.: A short history of SHELX. Acta Crystallogr. A64 (2008) 112-122.

3. Sheldrick, G. M.: Crystal structure refinement with SHELXL. Acta Crystallogr. C71 (2015) 3-8.

4. Farrugia, L. J.: WinGX and ORTEP for Windows: an update. J. Appl. Crystallogr. 45 (2012) 849-854.

5. Dakternieks, D.; Jurkschat, J.; van Dreumel, S.; Tiekink, E. R. T.: Molecular dynamics within diorganotin systems: solution and solid state studies of new mixed distannoxane dimers $\left[\mathrm{tBu}_{2}(\mathrm{Cl}) \mathrm{SnOSn}(\mathrm{Cl}) \mathrm{R}_{2}\right]_{2}$. Inorg. Chem. 36 (1997) 2023-2029.

6. Lo, K. M.; Lee, S. M.; Tiekink, E. R. T.: Crystal structure of octa(4-chlorobenzyl)-dichlorido-bis $\left(\mu_{2}\right.$-methanolato)-bis $\left(\mu_{3}\right.$ oxo)-tetratin(IV), $\mathrm{C}_{58} \mathrm{H}_{54} \mathrm{Cl}_{10} \mathrm{O}_{4} \mathrm{Sn}_{4}$. Z. Kristallogr. NCS 235 (2019) 175-177.

7. Hong, M.; Yang, Y.; Li, C.; Xu, L.; Li, D.; Li, C.: Study of the effect of molecular structure and alkyl groups bound with tin(IV) on their cytotoxicity of organotin(IV) 2-phenyl-4-selenazole carboxylates. RSC Adv. 5 (2015) 102885-102894.
8. Casas, J. S.; Castiñeiras, A.; Couce, M. D.; Sánchez, A.; Sordo, J.; Vázquez-López, E.: New tin-oxometallates from the hydrolysis of $\mathrm{SnEt}_{2}{ }^{2+}$ in the presence of 2,6-lutidine- $\alpha^{2}, 3$-diol and different anions. Chem. Sel. 2 (2017) 1983-1991.

9. Gielen, M.; Tiekink, E. R. T.: Metallotherapeutic drugs and metal-based diagnostic agents: the use of metals in medicine. John Wiley \& Sons Ltd: Chichester, England (2005) 421-439.

10. Addison, A. W.; Rao, T. N.; Reedijk, J.; van Rijn, J.; Verschoor, G. C.: Synthesis, structure, and spectroscopic properties of copper(II) compounds containing nitrogen-sulphur donor ligands; the crystal and molecular structure of aqua[1,7-bis( $N$ methylbenzimidazol-2'-yl)-2,6-dithiaheptane]- copper(II) perchlorate. J. Chem. Soc., Dalton Trans (1984) 1349-1356.

11. Turner, M. J.; McKinnon, J. J.; Wolff, S. K.; Grimwood, D. J.; Spackman, P. R.; Jayatilaka, D.; Spackman, M. A.: Crystal Explorer v17. The University of Western Australia, Australia (2017).

12. Tan, S. L.; Jotani, M. M.; Tiekink, E. R. T.: Utilizing Hirshfeld surface calculations, non-covalent interaction $(\mathrm{NCl})$ plots and the calculation of interaction energies in the analysis of molecular packing. Acta Crystallogr. E75 (2019) 308-318. 